\title{
Plasma nitrate concentration in infective gastroenteritis and inflammatory bowel disease
}

\author{
R S Dykhuizen, J Masson, G McKnight, A N G Mowat, C C Smith, L M Smith, \\ N Benjamin
}

\begin{abstract}
Background-In subjects on a low nitrate diet, plasma nitrate concentration and urinary nitrate excretion are thought to reflect endogenous nitric oxide (NO) production, and have been reported to increase during infective and inflammatory bowel disease.

Aims-To compare the extent of NO production in patients with infective versus non-infective forms of bowel dysfunction.

Subjects-Four groups: 20 healthy, volunteer clerical and laboratory staff, 12 patients with irritable bowel syndrome, 19 patients with inflammatory bowel disease, and 20 patients with infective gastroenteritis.

Methods-The plasma nitrate concentration was determined with a copper coated cadmium column and spectrophotometry. Mean and median plasma nitrate concentrations were calculated and compared within the four groups. Mann-Whitney distribution free rank testing was used to compare the median values.
\end{abstract}

Results-Median plasma nitrate concentrations in the four groups were: controls $32 \cdot 7 \mu \mathrm{mol} / \mathrm{l}$; irritable bowel syndrome $35 \cdot 5$ $\mu \mathrm{mol} / \mathrm{A}$; inflammatory bowel disease $35 \cdot 1$ $\mu \mathrm{mol} / \mathrm{l}$; and gastroenteritis $117.9 \mu \mathrm{mol} / \mathrm{l}$ $(\mathbf{p}<0.001$ gastroenteritis $v$ all other groups).

Conclusions-Plasma nitrate concentration could serve as a discriminant between infective and inflammatory or functional bowel disease in patients presenting with diarrhoea. It is not clear why there is considerable difference in endogenous nitrate synthesis in these two conditions, which are both characterised by severe gut inflammation.

(Gut 1996; 39: 393-395)

Keywords: nitric oxide, infective gastroenteritis, inflammatory bowel disease.

In humans, plasma and urinary nitrate were thought to originate from dietary intake or production by micro-organisms in the intestine. ${ }^{1}$ It was subsequently shown that nitrate is synthesised in both germ free rats ${ }^{2}$ and in humans, ${ }^{3}$ and that murine macrophages produce large amounts of nitrate when stimulated by bacterial products ${ }^{4}$ with nitric oxide (NO) as the precursor of nitrate. ${ }^{5}$
Under certain circumstances, humans also respond to infection and inflammation by increased endogenous production of NO via the L-arginine-NO pathway. ${ }^{6}$ Plasma nitrate concentration is raised in septic shock ${ }^{7}$ and has been implicated in the pathogenesis of hypotension $^{8}$ in this condition. Nitrate is the stable end product of $\mathrm{NO}$ oxidation and plasma and urinary concentrations are thought to reflect endogenous NO production in subjects with a low dietary intake of nitrate. ${ }^{6}$

Recently we found a dramatic increase in plasma nitrate concentration and urinary nitrate excretion in patients with infective gastroenteritis. ${ }^{9}$ A strong correlation between nitrate production and severity of diarrhoea was shown. It has been reported that endogenous synthesis of $\mathrm{NO}$ is also increased in inflammatory bowel disease. ${ }^{10-16}$ However, data on plasma nitrate concentration in this condition is sparse, and when mentioned, values are lower than we have found in our patients with infective gastroenteritis. This study therefore compares plasma nitrate concentrations in patients admitted to hospital with infective gastroenteritis and inflammatory bowel disease, using healthy volunteers and patients with irritable bowel syndrome as controls.

\section{Methods}

The study was carried out at the Infection Unit and the Department of Gastroenterology at Aberdeen Royal Infirmary, with approval of the local joint ethics committee. Four groups were identified: (a) The control group consisted of healthy volunteer clerical and laboratory staff on a low nitrate diet $(<100$ $\mu \mathrm{mol} /$ day). (b) Patients with irritable bowel syndrome were recruited from the gastroenterology outpatient department. They had the characteristic symptomatology of the condition and a stool frequency $>3$ per day. Rectal examination, sigmoidoscopy and biopsy, and stool cultures disclosed no abnormalities. The patients' dietary nitrate intake was unrestricted. (c) Patients with inflammatory bowel disease admitted with an exacerbation of their disease. All had a stool frequency $>3$ per day and raised $C$ reactive protein concentrations, indicating active disease. Nitrate intake was variable depending on the severity of the exacerbation but generally low; most patients were nil by mouth on fluid replacement therapy (no nitrate); the remainder were on a low residue diet with little nitrate. The diagnosis of inflammatory bowel 
Mean (SEM) and median blood plasma concentrations of nitrate in healthy controls, patients with irritable bowel syndrome (IBS), patients with inflammatory bowel disease (IBD), and patients with infective gastroenteritis

\begin{tabular}{lllcccc}
\hline & $\begin{array}{l}\text { No of } \\
\text { patients }\end{array}$ & Age $(y)$ & Sex $(M / F)$ & \multicolumn{3}{c}{ Plasma nitrate concentration (mmoll) } \\
\cline { 5 - 7 } & & & & Mean $(S D)$ & (Median) & p Value ${ }^{\star}$ \\
\hline Controls & 20 & $21-57$ & $9 / 11$ & $35 \cdot 9(2 \cdot 1)$ & $32 \cdot 8$ & \\
IBS & 12 & $18-42$ & $5 / 7$ & $33 \cdot 4(3 \cdot 7)$ & $35 \cdot 5$ & NS \\
IBD & 19 & $18-69$ & $11 / 8$ & $47 \cdot 7(8 \cdot 0)$ & $35 \cdot 1$ & NS \\
Gastroenteritis & 20 & $18-74$ & $8 / 12$ & $228 \cdot 5(72 \cdot 0)$ & $117 \cdot 7$ & $<0 \cdot 001$ \\
\hline
\end{tabular}

^Mann-Whitney $U$ test for median value.

disease was confirmed radiologically and histologically in all patients and all patients had negative stool cultures. (d) Patients with microbiologically established infective gastroenteritis were recruited from admissions to the Infection Unit. All were on intravenous fluid replacement therapy (no nitrate) and had a stool frequency $>3$ per day.

Blood samples for plasma nitrate measurement were taken within four hours of admission to hospital in the patients with inflammatory bowel disease and infective gastroenteritis. The assay was performed as previously described ${ }^{17}$ with a copper coated cadmium reduction column and spectrophotometry, modified by replacing the carrier fluid with $1.5 \%$ glycine, $\mathrm{pH} 9.4$. In this assay the column reduces nitrate to nitrate before measurement. Plasma urea and creatinine were measured by standard autoanalyser methods and those patients with a urea concentration $>10 \mathrm{mmol} / \mathrm{l}$ or creatinine concentration $>125$ $\mu \mathrm{mol} / \mathrm{l}$ were excluded from the study.

Mean and median plasma nitrate concentrations were calculated and compared within the four patient groups. Mann-Whitney distribution free rank testing was used to compare the median values.

\section{Results}

The Table gives the mean (SEM) and median plasma nitrate concentrations of the four patient groups and the Figure shows the distribution of data. Only the gastroenteritis group showed a significantly increased median

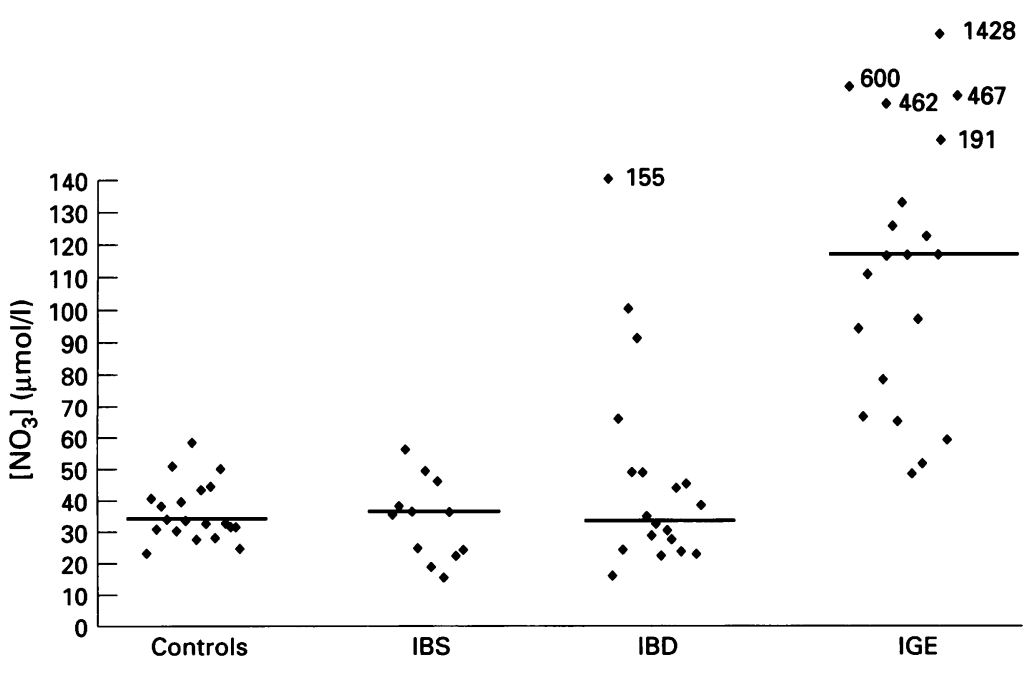

Plasma nitrate concentrations $\left(\mathrm{NO}_{3} ; \mu \mathrm{mol} /\right)$ of controls, and patients with irritable bowel syndrome (IBS), inflammatory bowel disease (IBD), or infective gastroenteritis (IGE). plasma nitrate concentration compared with controls $(\mathrm{p}<0.001)$.

Two patients in the inflammatory bowel disease group were initially admitted to the Infection Unit with the provisional diagnosis of infective gastroenteritis, but stool cultures were negative, and they proved subsequently to have inflammatory bowel disease. The plasma nitrate concentrations in these two patients were $23.0 \mu \mathrm{mol} / 1$ and $16 \cdot 1 \mu \mathrm{mol} / 1$. One patient was admitted with a clinical diagnosis of exacerbation of inflammatory bowel disease but was found to have toxin positive infection with Clostridium difficile; his plasma nitrate concentration was $123.8 \mu \mathrm{mol} / 1$.

Seven patients in the inflammatory bowel disease group had Crohn's disease and 12 had ulcerative colitis. There was no significant difference in the mean or median values of these two subgroups: mean Crohn's disease $42.9(11.5) \mu \mathrm{mol} / 1$ (median $30.6 \mu \mathrm{mol} / \mathrm{l}$ ) and mean ulcerative colitis $50.7(11.0) \mu \mathrm{mol} / \mathrm{l}$ (median $41.5 \mu \mathrm{mol} / \mathrm{l}$ ). Seven patients in the inflammatory bowel disease group were receiving immunosuppressive therapy, but there were no significant differences in mean or median values (mean inflammatory bowel disease plus immunosuppressive therapy $61 \cdot 3$ $(18.5) \mu \mathrm{mol} / \mathrm{l}$ (median $38.8 \mu \mathrm{mol} / \mathrm{l}$ ) and mean inflammatory bowel disease on no immunosuppressive therapy $39.9(6.4) \mu \mathrm{mol} / \mathrm{l}$ (median $32.0 \mu \mathrm{mol} / \mathrm{l})$ ). Four patients had total colectomy performed within three days of plasma nitrate measurement because the disease was inadequately controlled on medical treatment alone: one patient with Crohn's disease (plasma nitrate $30.6 \mu \mathrm{mol} / \mathrm{l}$ ) and three patients with ulcerative colitis (plasma nitrate $24 \cdot 3,32 \cdot 3$, and $38.8 \mu \mathrm{mol} / \mathrm{l})$.

All the patients (20) in the infective gastroenteritis group had stool culture positive infective gastroenteritis: Campylobacter jejuni (10), Shigella sonnei (five), Clostridium difficile (toxin positive) (three), Salmonella enteriditis (one), and Escherichia coli 0157 (one).

\section{Discussion}

Activation of the L-arginine-NO pathway has been shown in rectal biopsy specimens from patients with the histological hallmarks of inflammatory bowel disease. ${ }^{11}{ }^{13}{ }^{16}$ Increased NO concentrations have also been directly measured in the lumen of affected bowel segments, ${ }^{15}$ and there is evidence that the inducible insoform of NO synthase is involved. ${ }^{18}$ However, it is evident from the present report that in the majority of patients with inflammatory bowel disease the L-arginine-NO pathway is not sufficiently activated to give rise to increased plasma nitrate concentrations, even during severe exacerbations. By contrast, infective gastroenteritis was invariably accompanied by a rise in plasma nitrate concentration, and the amount of increase showed a good correlation with severity of disease. ${ }^{9}$

Measurement of the plasma nitrate concentration may serve as a rapid, simple, and noninvasive test to differentiate between infective 
and non-infective disease in patients presenting with diarrhoea. With an upper limit of normal of $50 \mu \mathrm{mol} / \mathrm{l}$, this measurement would have produced a sensitivity of $95 \%$ and a specificity of $84 \%$ for the patients in this study. In present hospital practice it takes three to five days to differentiate infective from inflammatory disease. A normal plasma nitrate concentration in a patient with a provisional diagnosis of infective gastroenteritis would strongly suggest alternative disease, and a raised nitrate concentration in inflammatory bowel disease may indicate associated infection. A plasma nitrate result shortly after admission might help to decide on appropriate patient referral and need for isolation. Further studies are indicated to define the optimal cut off concentration of plasma nitrate to distinguish between infective and inflammatory disease.

The source of plasma nitrate in patients with infective gastroenteritis remains unknown. Impaired excretion of nitrate as the cause of the plasma rise is excluded because the renal function of our patients was normal and we have previously shown that urinary excretion of nitrate is also increased during infective gastroenteritis. Micro-organisms in the small and large intestine, commensal or pathogen, are not known to produce nitrate. The rise in plasma nitrate concentration is most probably a reflexion of increased endogenous NO production by the host. The NO is rapidly oxidised to nitrite under physiological conditions and in the presence of haemoglobin nitrate is formed as the stable end product. ${ }^{6}$ In the absence of dietary intake, no other sources of nitrate are presently recognised in mammalian systems to explain the increase in plasma nitrate concentration.

The cause of the difference in endogenous nitrate production between inflammatory bowel disease and infective gastroenteritis remains speculative. Possibly NO synthase is induced throughout the small and large bowel during infection compared with much more localised induction during inflammation. Perhaps the enzyme is specifically induced by bacterial products. It is of interest that plasma nitrate is concentrated up to 10 times by the salivary glands, and reduced to nitrite by micro-organisms present on the tongue. Once the salivary nitrite is swallowed, it will generate $\mathrm{NO}$ in the acid conditions prevailing in the stomach. The bactericidal action of acidified nitrite may protect the host from faecal-oral reinfection during episodes of infective gastroenteritis. ${ }^{19}$ Whether the abundant NO production during infective gastroenteritis has any effect on the haemodynamic stability of the patient, already compromised by fluid loss due to diarrhoea or vomiting, remains to be elucidated.

More research is needed to understand the pathophysiological processes underlying the discrepancy in plasma nitrate concentration during infective versus inflammatory bowel disease. Exact identification of the location, isoform, and activity of the NO synthase involved in the two conditions seems the next logical step.

1 Tannenbaum SR, Fett D, Young VR. Nitrite and nitrate are formed by endogenous synthesis in the human intestine. Science 1978; 200: 1487-9.

2 Green LC, Tannenbaum SR, Goldman P. Nitrate synthesis in the germ-free and conventional rat. Science 1981; 212: 56-8.

3 Green LC, de Luzuiraga KR, Wagner DA, Rand W, Istfan N, Young VR, et al. Nitrate biosynthesis in man. Proc Natl Acad Sci USA 1981; 78: 7764-8.

4 Hibbs JB, Tanitor RR, Vavrin Z. Macrophage cytotoxicity: role for L-arginine deaminase and amino nitrogen role for L-arginine deaminase and amino
oxidation to nitrite. Science 1987; 235: 473-6.

oxidation to nitrite. Science $1987 ; 235: 473-6$.
5 Hibbs JB, Tanitor RR, Vavrin Z, Rachlin EM. Nitric oxide: a cytotoxic activated macrophage effector molecule. Biochem Biophys Res Commun 1988; 157: 87-94.

6 Hibbs JB Jr, Westenfelder C, Taintor R, Vavrin Z, Kablitz C, Baranowski RL, et al. Evidence for cytokine-inducible nitric oxide synthesis from $L$-arginine in patients receiving interleukin-2 therapy. $\mathcal{F}$ Clin Invest 1992; 89: 867-77.

7 Neilly IJ, Copland M, Haj M, Adey G, Benjamin N, Bennett B. Plasma nitrate concentrations in neutropenic and nonneutropenic patients with suspected septicaemia. $\mathrm{Br} \mathcal{F}$ Haematol 1995; 89: 199-202.

8 Petros A, Lamb G, Leone A, Moncada S, Bennett D, Vallance $P$. Effects of nitric oxide synthase inhibitor in humans with septic shock. Cardiovasc Res 1994; 28: human

9 Dykhuizen RS, Copland M, Smith CC, Douglas JG, Benjamin N. Plasma nitrate concentration and urinary nitrate excretion in patients with Gastroenteritis. $\mathcal{F}$ Infect 1995; 31: 73-5.

10 Wettig K, Schulz KR, Scheibe J, Diener W, Fisher G, Namaschk A. Endogenous nitrate synthesis in selected infectious diseases and ulcerative colitis. Neoplasma 1991; 38: $337-41$.

11 Middleton SJ, Shorthouse $M$, Hunter JO. Increased nitric oxide synthesis in ulcerative colitis. Lancet 1993; 341: 465-6.

12 Tran DD, Visser JJ, Pool MO, Cuesta MA, Hoekman K, in inflammatory bowel disease. Lancet 1993; 341: 1150 .

13 Boughton-Smith NK, Evans SM, Hawkey CJ, Cole AT, Balsitis M, Whittle BJR, et al. Nitric oxide synthase activity in ulcerative colitis and Crohn's disease. Lancet 1993; 342: 338-40.

14 Melichar B, Karlicek R, Tichy M. Increased urinary nitrate excretion in inflammatory bowel disease. Eur $\mathfrak{f}$ Chem Clin Biochem 1994; 32: 3-4.

15 Lundberg JO, Hellstrom PM, Lundberg JM, Alving K. Greatly increased luminal nitric oxide in ulcerative colitis. Lancet 1994; 344: 1673-4.

16 Rachmilewitz D, Stamler JS, Bachwich D, Karmeli F, Ackerman Z, Podolsky DK. Enhanced colonic nitric oxide generation and nitric oxide synthase activity in oxide generation and nitric oxide synthase activity in
ulcerative colitis and Crohn's disease. Gut 1995; 36: ulcerative

17 Green LC, Wagner DA, Glogowski J. Analysis of nitrate, nitrite and ${ }^{15} \mathrm{~N}$ nitrate in biological fluids. Anal Biochem 1982; 126: 131 .

18 Singer II, Kawka DW, Scott S, Weidner J, Mumford R, Stenson WF. Inducible nitric oxide synthase and nitrotyrosine are localised in damaged intestinal epithelium during human inflammatory bowel disease (IBD) [abstract of the fourth international meeting, biology of nitric oxide]. Endothelium 1995; 3 (suppl 105): 417.

19 Duncan C, Dougall H, Johnston P, Green S, Brogan R, Leifert $C$, et al. Chemical generation of nitric oxide in the mouth from the enterosalivary circulation of dietary nitrate. Nature Medicine 1995; 1: 546-51. 